OPEN ACCESS

Edited by:

Olivier Girard,

Murdoch University, Australia

Reviewed by:

Domingo J. Ramos-Campo, Catholic University of Murcia, Australia Nathan Elsworthy,

Central Queensland University, Australia

*Correspondence:

Lara Rodríguez-Zamora lara.rodriguez-zamora@oru.se

Specialty section This article was submitted to Elite Sports and Performance

Enhancement,

a section of the journal

Frontiers in Sports and Active Living

Received: 02 August 2019 Accepted: 10 October 2019 Published: 24 October 2019

Citation:

Rodríguez-Zamora L, Padial $P$, Schoenfeld BJ and Feriche B (2019) Mean Propulsive Velocity Is a Viable Method for Adjusting the Resistance-Training Load at Moderate Altitude.

Front. Sports Act. Living 1:52 doi: 10.3389/fspor.2019.00052

\section{Mean Propulsive Velocity Is a Viable Method for Adjusting the Resistance-Training Load at Moderate Altitude}

\author{
Lara Rodríguez-Zamora ${ }^{1,2 *}$, Paulino Padial ${ }^{3}$, Brad Jon Schoenfeld ${ }^{4}$ and Belén Feriche ${ }^{3}$ \\ ${ }^{1}$ Division of Sport Sciences, School of Health and Medical Sciences, Örebro University, Örebro, Sweden, ${ }^{2}$ Environmental \\ Physiology Group, Department of Health Sciences, Mid Sweden University, Östersund, Sweden, ${ }^{3}$ Department of Physical \\ Education and Sport, Faculty of Sport Sciences, University of Granada, Granada, Spain, ${ }^{4}$ Department of Health Sciences, \\ Lehman College, New York, NY, United States
}

We examined the viability of using mean propulsive velocity (MPV) to adjust the load in the countermovement jump (CMJ) at moderate altitude. Twenty-four volunteers were assigned to a 4-week power-oriented resistance training $\left(R_{T}\right)$ program in either normoxia $(\mathrm{N}, 690 \mathrm{~m})$ or intermittent hypobaric hypoxia $(\mathrm{H}, 2,320 \mathrm{~m})$. The load was adjusted to maintain execution velocity of $\mathrm{CMJ}$ at $1 \mathrm{~m} \cdot \mathrm{s}^{-1}$ of MPV. Relative peak power output $\left(P_{\text {rel }}\right)$, and percentage of velocity loss throughout the sets $(V L)$ were determined for each session. The internal load was measured by the rating of perceived exertion (RPE). The absolute load lifted was higher in IH compared to N $(75.6 \pm 8.4$ vs. $58.5 \pm 12.3 \mathrm{~kg} P<$ 0.001). However, similar relative increases for both groups were found when comparing the final values $(\mathrm{IH}: 8.2 \%, P=0.007 ; \mathrm{N}: 9.8 \%, P=0.03)$ with no changes in $\mathrm{VL}$ between groups $(P=0.36)$. Post-study $P_{\text {rel }}$ improved significantly only in $\mathrm{H}\left(+7 \% \mathrm{~W} \cdot \mathrm{kg}^{-1}\right.$, $P=0.002)$. Mean RPE was greater in $I H$ vs. $N(6.8 \pm 1.5$ vs. $5.6 \pm 2, P<0.001)$. The MPV seems to be a viable method for adjusting external load during $\mathrm{R}_{\mathrm{T}}$ at moderate altitude. However, given that $\mathrm{R}_{T}$ at moderate altitude increases RPE, it is prudent to monitor internal load when using the MPV to best determine the actual physiological stress of the session.

Keywords: hypobaric hypoxia, monitoring, power, resistance training, strength

\section{INTRODUCTION}

Altitude training (usually at moderate altitudes of $1,800-2,500 \mathrm{~m}$ ) is a strategy widely used by athletes to improve performance at sea level. In terms of resistance training $\left(\mathrm{R}_{\mathrm{T}}\right)$, it has been found that hypoxia elicits specific adaptations, such us muscle plasticity, that modify the muscles' capacity to generate work resulting from a sensitivity to oxygen changes (Bosco et al., 2010). In addition, explosive actions seemingly benefit from hypobaric hypoxia exposure due to the decreased air resistance and modified motor unit recruitment patterns as a result of the increased anaerobic metabolism release (Scott et al., 2016b,c; Ramos-Campo et al., 2017). To this end, improvements in sprinting, throwing, and jumping performance at altitude have been reported after exposure to hypobaric hypoxia (Hamlin et al., 2015). This may be attributable not only to the mechanisms mentioned above, but also to the increased spinal excitability in acute exposure 
to hypoxia (Lundby et al., 2009), by which continuous exposure would not be needed to achieve muscle power improvements (Morales-Artacho et al., 2018). Accordingly, it has been shown that both acute and prolonged exposure to moderate altitude improved maximal power, movement velocity, and jump performance (Feriche et al., 2014; García-Ramos et al., 2016b).

On the other hand, a means to determine whether a $R_{T}$ program is efficacious is by quantifying the associated stress imposed on the athlete (Scott et al., 2016a). When the training load is insufficient then adaptation might not occur, while excessive stress might impair performance and potentially increase injury risk (Halson, 2014). Hence, coaches record markers of internal [i.e., the athlete's individual responses, such as heart rate (HR) and ratings of perceived exertion (RPE)] and external (i.e., the work completed by the athlete, in terms of variables such as velocity, applied strength, and power output) loads to quantify the training stress and hence gauge the training efficacy (McLaren et al., 2017). In an attempt to integrate both the training session volume and intensity as a single variable, the use of session ratings of perceived exertion (sRPE $\times$ training time in $\mathrm{min}$ ) provide a valid and reliable measure of the internal training load (Day et al., 2004; Sweet et al., 2004). A benefit of this strategy is that RPE considers the actual loads being lifted in concert with the number of repetitions, inter-set rest periods, and velocity of repetitions during the session (Scott et al., 2016a). Alternatively, several studies have indicated a close relationship between training intensity and the velocity achieved against a given absolute load, and the strength responses (GonzálezBadillo et al., 2011, 2014). González-Badillo and Sánchez-Medina (2010) introduced the concept of the mean propulsive velocity (MPV) as an alternative way to prescribe loading intensity to the 1RM by using the movement velocity. The authors justified its use based on the fact that the actual velocity performed in each repetition could perhaps be the best reference to gauge the real effort incurred by the athlete. Consequently many coaches and athletes have embraced "velocity-based training" as a strategy for adjusting the intensity of the $\mathrm{R}_{\mathrm{T}}$ programs. However, during $\mathrm{R}_{\mathrm{T}}$ in isoinertial conditions, and assuming that with every repetition performed with maximal voluntary effort, velocity unintentionally declines as fatigue develops (Izquierdo et al., 2006). In fact, strong correlations were found between mechanical [velocity and countermovement jump (CMJ) height losses] and metabolic (lactate, ammonia) measures of fatigue supporting the validity of using velocity loss (VL) to objectively quantify neuromuscular fatigue during $\mathrm{R}_{\mathrm{T}}$ (Sánchez-Medina and González-Badillo, 2011).

Environmental conditions, such as altitude, could produce neuromuscular fatigue during exercise by decreasing the force or power capacity (Amann and Calbet, 2008) as well as the muscle fibers' capacity for relaxation (Allen et al., 2008), Indeed, the reduction of oxygen delivery to the working muscles in hypoxia could exacerbate fatigue by impairing neuromuscular transmission during contractions (Amann et al., 2006). As a result, the same exercise carried out at altitude could be physiologically more demanding than at sea level so that higher altitudes induce a higher fatigue. Given these results and the aforementioned effects of hypoxia on muscle performance, it seems plausible that the force-velocity relationship at altitude could be affected by environmental conditions, making the adjustment of the load via MPV different than at sea level. Thus, the principal aim of this study was to examine if MPV is a viable tool to adjust the individual load during a power-oriented $\mathrm{R}_{\mathrm{T}}$ program at moderate altitude. We hypothesized that similar load and VL patterns would be seen with the load properly adjusted in both groups.

\section{MATERIALS AND METHODS}

The present study used a longitudinal design with two parallel groups [living and training in normoxia $(\mathrm{N} ; n=11)$, and living in $\mathrm{N}$ and training at intermittent moderate altitude $(\mathrm{IH}$; $2,320 \mathrm{~m}) ; n=13$ ] to compare the changes in variables linked to a $1 \mathrm{~m} \cdot \mathrm{s}^{-1}$ of MPV (Loturco et al., 2015) [load lifted (kg) and peak power output $(\mathrm{W})$-both in absolute and relative values, and the percentage of velocity loss throughout the sets (\%, $\mathrm{VL}$ )] when executing a countermovement jump (CMJ) during a 4-week power-oriented $\mathrm{R}_{\mathrm{T}}$ program. The internal load was measured by the RPE (Morree et al., 2012). Subjects performed two $\mathrm{R}_{\mathrm{T}}$ sessions - week ${ }^{-1}$ (eight in total) under the two different conditions. The subjects were assigned to each group according to their availability, making this a quasi-experimental design. The IH group conducted the training sessions at the HighPerformance Center in Sierra Nevada $(2,320 \mathrm{~m})$, while the $\mathrm{N}$ group trained at the Faculty of Sport Sciences laboratory (690 m). In order to avoid injuries and to standardize technique before the $\mathrm{R}_{\mathrm{T}}$ program, all of the volunteers took part in a pre-intervention 4 -week conditioning-training program. At the beginning of the study there were no significant differences between groups in terms of absolute load lifted (IH: $68.0 \mathrm{~kg}$ vs. N: $60.5 \mathrm{~kg}, P>$ 0.05 ) and $\mathrm{P}_{\text {rel }}$ at $1 \mathrm{~m} \cdot \mathrm{s}^{-1}$ of the MPV (IH: $47.2 \mathrm{~W} \cdot \mathrm{kg}^{-1}$ vs. N: $\left.43.9 \mathrm{~W} \cdot \mathrm{kg}^{-1}, P>0.05\right)$, tested in normoxia. To minimize the potential for instruction bias, the testers remained the same for both groups.

\section{Subjects}

Twenty-four collegiate-men with at least 2 years of $\mathrm{R}_{\mathrm{T}}$ experience volunteered for the study. The mean $\pm \mathrm{SD}$ of age, height, body mass, BMI, fat mass, and fat free mass were; $23.0 \pm 3.3$ years, $177.8 \pm 6.9 \mathrm{~cm}, 75.9 \pm 8.5 \mathrm{~kg}, 23.9 \pm 1.6 \mathrm{~kg} \cdot \mathrm{m}^{-1}, 13.4 \pm 3.2 \mathrm{~kg}$, and $45.0 \pm 4.2 \mathrm{~kg}$, respectively. The inclusion criteria were: not having been exposed to more than 3-4 days of altitudes in excess of 1,500 m within 2 months before the study; no chronic diseases or recent musculoskeletal injuries, and not currently using drugs/ergogenic aids that could impact muscular function. Subjects received oral and written information before giving their informed consent. This study was approved by the local Research Ethics Committee and conducted in accordance with the Helsinki Declaration.

\section{Procedures}

\section{Pre-intervention}

After a general and specific warm-up (5 min jogging, joint mobility exercises, and five unloaded CMJ), subjects completed a CMJ test using the following loads under normoxic conditions: 


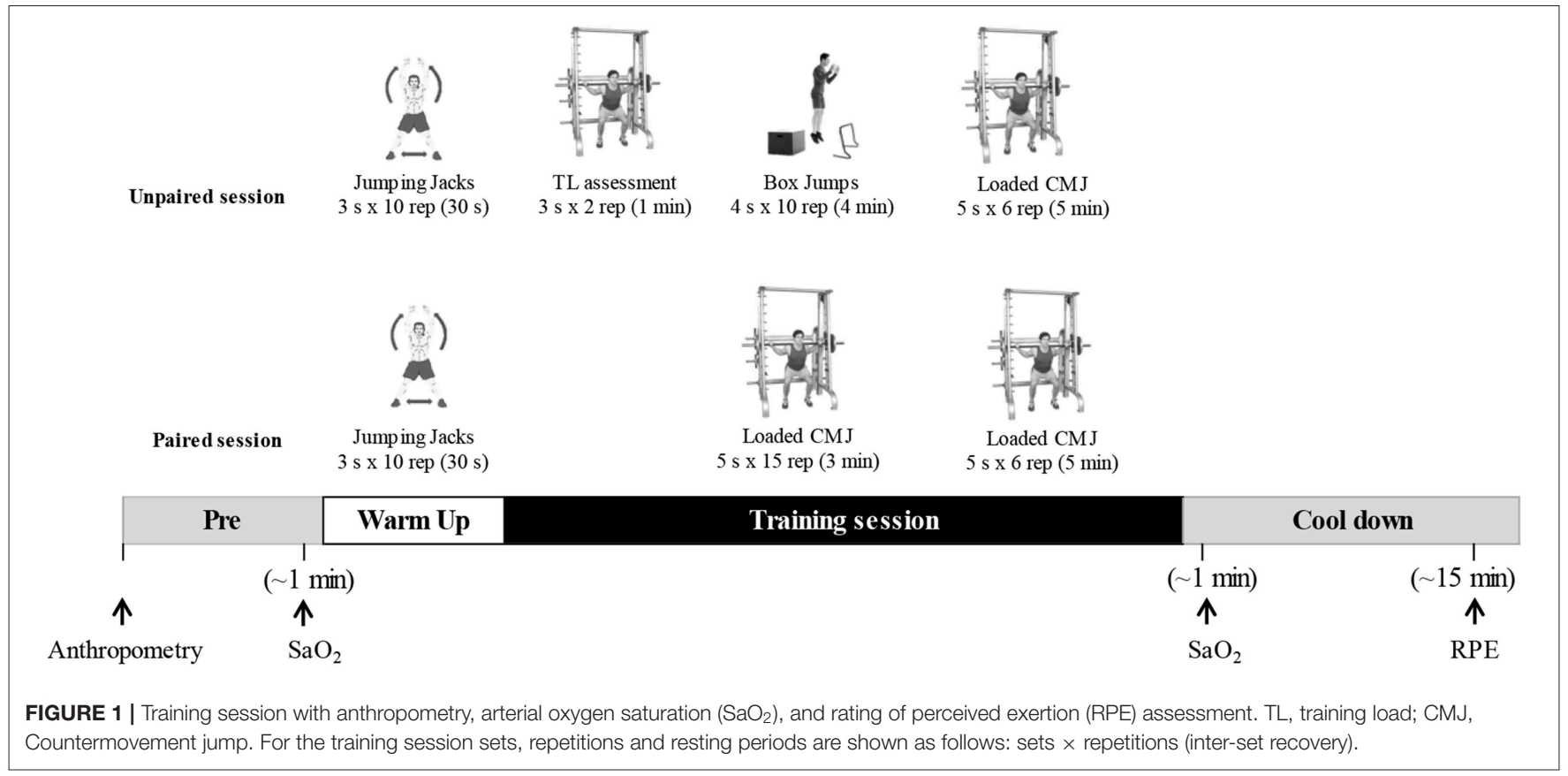

17, 30, 45, 60, and $75 \mathrm{~kg}$ (Morales-Artacho et al., 2018). Two attempts were performed for each load with a 1 min pause between repetitions and a 3 min pause between loads (MoralesArtacho et al., 2018). Subjects were instructed to perform the CMJ with $\sim 90^{\circ}$ of knee flexion, and to jump as high as possible. For every repetition the MPV was recorded and the repetition with the highest MPV was selected for further analysis. Fifteen minutes after the test, subjects carried out a 15-repetition CMJ test at maximum intended velocity (MoralesArtacho et al., 2018). The external load used during the test was individually selected as the load linked with the barbell MPV of $1 \mathrm{~m} \cdot \mathrm{s}^{-1}$, interpolated from the load-velocity relationship achieved on that day. The average $\mathrm{P}_{\text {rel }}$ of the set was used for further comparisons.

\section{Training Session}

Subjects performed 4 weeks (two sessions - week ${ }^{-1}$ ) of a poweroriented training program (Figure 1) (Morales-Artacho et al., 2018). Each session began with a $15 \mathrm{~min}$ warm up (5 min of aerobic activity, $5 \mathrm{~min}$ of lower-body mobility exercises, and three sets of 10 repetitions of jumping jacks). After the warmup, five sets of six loaded CMJs were performed with a load linked to $1 \mathrm{~m} \cdot \mathrm{s}^{-1}$ of the MPV, each with a $5 \mathrm{~min}$ inter-set rest period. This load-velocity ratio is considered optimal for muscle power training using CMJ exercise and corresponds to $50-55 \%$ of 1 repetition maximum (Pérez-Castilla et al., 2018). Subjects jumped as high as possible after performing a countermovement jump to a self-selected depth of $\sim 90^{\circ}$ knee flexion (JiménezReyes et al., 2017). In addition, on the first day of every week (unpaired session), the loaded CMJ was preceded by four sets of 10 box jumps at different heights and depths with a 4 min rest, while on the second day (paired session), it was preceded by five sets of 15 CMJs followed by a 3 min rest between sets executed under the same conditions as the loaded CMJ.

\section{External Training Load Adjustment}

The load displaced at a velocity of $1 \mathrm{~m} \cdot \mathrm{s}^{-1}$ of the MPV was assessed weekly during the training program. For this determination, subjects performed three sets of two CMJs after the warmup of the first training session of the week. The initial load was set at $20 \mathrm{~kg}$ for all subjects and then progressively increased three times (by 15-20 kg each time) until the MPV was lower than $0.9 \mathrm{~m} \cdot \mathrm{s}^{-1}$. For every increment, two attempts were executed with a $1 \mathrm{~min}$ inter-rep rest and a 3 min rest between load changes. The exact load linked to a $1 \mathrm{~m} \cdot \mathrm{s}^{-1}$ of the MPV was calculated by interpolation from the individual load-MPV linear regression equation.

\section{Measurements}

\section{External load markers}

All loaded CMJs were performed using a Smith Machine (Technogym, Barcelona, Spain). MPV data was obtained from a linear velocity transducer (T-Force System; Ergotech, Murcia, Spain). The dynamic measurement system was fixed perpendicular to the bar with a tether, reporting the vertical velocity at $1000 \mathrm{~Hz}$. The variables were: (1) the displaced load (in $\mathrm{kg}$ at $1 \mathrm{~m} \cdot \mathrm{s}^{-1}$ of the MPV); (2) the maximal relative power achieved during the concentric phase of the movement $\left(\mathrm{W} \cdot \mathrm{kg}^{-1}\right.$, $\left.\mathrm{P}_{\text {rel }}\right)$, and; (3) the percentage of velocity loss $(\%, \mathrm{VL})$, defined as the change in average peak velocity during the execution of the first and second rep vs. the fifth and sixth rep during the same loaded CMJ set. The daily VL average during the whole $\mathrm{R}_{\mathrm{T}}$ program was calculated and differences between the first session compared to the others (from two to eight) were used for comparisons.

\section{Arterial oxygen saturation}

Immediately before and after each testing session, arterial oxygen saturation $\left(\mathrm{SaO}_{2}\right)$ was measured per duplicate using a pulse 
TABLE 1 | Mean values of external and internal training load markers per group.

\begin{tabular}{llcc}
\hline \multirow{2}{*}{ Load markers } & \multicolumn{2}{c}{ Groups } \\
\cline { 3 - 4 } & & $\mathbf{I H}(\boldsymbol{n}=\mathbf{1 1})$ & $\mathbf{N}(\boldsymbol{n}=\mathbf{1 3})$ \\
\hline External & Absolute displaced load $(\mathrm{kg})$ & $75.6 \pm 8.4^{\#}$ & $58.5 \pm 12.3$ \\
& Relative displaced load $\left(\mathrm{kg} \cdot \mathrm{kg}^{-1}\right)$ & $1.0 \pm 0.1^{\#}$ & $0.8 \pm 0.2$ \\
& Absolute power $(\mathrm{W})$ & $3,580.5 \pm 394.5^{\#}$ & $3,261.5 \pm 492.4$ \\
& Relative power $\left(\mathrm{W} \cdot \mathrm{kg}^{-1}\right)$ & $46.9 \pm 4.5^{\#}$ & $42.7 \pm 4.8$ \\
\hline Internal & RPE (a.u) & $6.8 \pm 1.5^{\#}$ & $5.6 \pm 2.1$ \\
\hline
\end{tabular}

Data are mean $\pm S D(n=24)$ for the 4-weeks $R_{T}$ program. $1 H$, intermittent hypoxia group; $N$, normoxia group. Significance $\#(P<0.001)$.

oximeter (Wristox 3100; Nonin, Plymouth, MN, USA). $\mathrm{SaO}_{2}$ values were calculated as the average for every $5 \mathrm{~s}$ period. The averaged pre- and -post-session $\mathrm{SaO}_{2}$ values were considered for further analysis.

\section{Rating of perceived exertion}

The RPE was rated $\sim 15$ min after the session using the Borg CR10 scale (Foster et al., 2001). To ensure the quality of the data collected, all subjects were instructed on the use of the CR-10 scale 1 week prior to starting the training protocol. In addition, their usage of the CR-10 scale was monitored during this week on three separate sessions (Psycharakis, 2011). Given that all sessions had the same duration, the RPE value, instead of the session-RPE, was considered for further analysis.

\section{Statistical Analysis}

Data are presented as means and standard deviations (SD). Normality was assessed using the Shapiro-Wilk's test. A threefactor mixed model ANOVA with a between-subject factor $(\mathrm{N}$ vs. IH) and two within-subject factors [(session: from the first to eighth) and time (pre-post training session)] were applied on $\mathrm{SaO}_{2}$. Another ANOVA with one between-subject factor $(\mathrm{N}$ vs. $\mathrm{IH}$ ) and one within-subject factor (session: from the first to eighth) was used for the load, $\mathrm{P}_{\text {rel }}$ and VL comparisons. A two factor ANOVA was used to evaluate the effect of the environmental conditions ( $\mathrm{N}$ vs. $\mathrm{IH}$ ) and the time (prepost session) on the variables: load and $\mathrm{P}_{\text {rel }}$. The withinsubject effect was determined using the Greenhouse-Geisser test or the Huynh-Feldt correction for degrees of freedom in cases where the result of the Mauchly sphericity test was significant. Bonferroni post-hoc tests was used for multiple pairwise comparisons. Eta squared $\left(\eta_{p}^{2}\right)$ for main effects were calculated for the ANOVAs, where the values of the effect sizes were considered as follows: 0.02 (small), 0.13 (medium), and 0.26 (large) (Bakeman, 2005). Friedman and Mann-Whitney $\mathrm{U}$ tests were used to analyze changes in the RPE. Pearson correlations were employed to quantify the association between markers of external load and the VL for each group. The level of significance was set $a$ prior $i$ at $P<0.05$. Statistical analyses were conducted using SPSS Statistics for Windows (v. 22; IBM Corp., Armonk, NY).

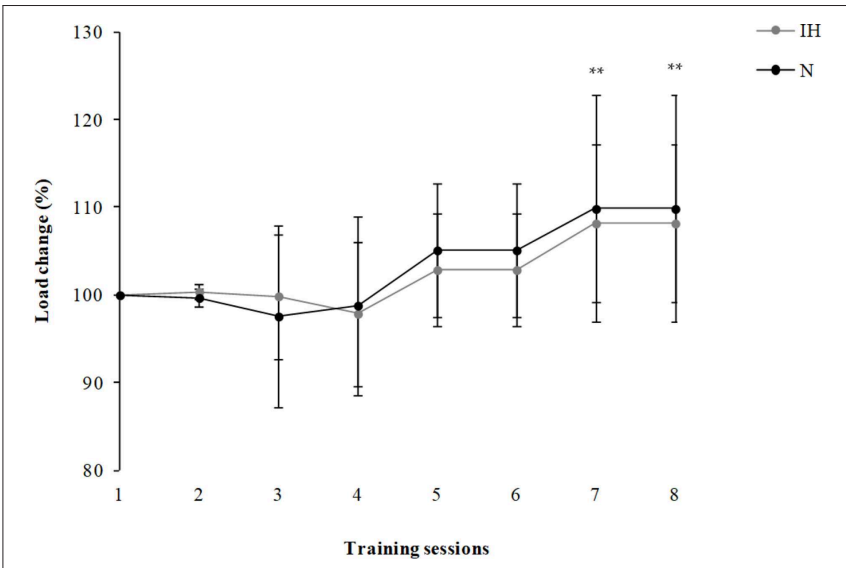

FIGURE 2 | Change in the training load that elicits $1 \mathrm{~m} \cdot \mathrm{s}^{-1}$ of the mean propulsive velocity (MPV) expressed in percentage (\%) for the 8 sessions of the resistance training program. ${ }^{*}$ Significant differences among sessions (compared with the first session, $P<0.05$ ) were noted for both groups.

\section{RESULTS}

\section{External Load Markers}

On average, the absolute load lifted was $22.6 \%$ higher in the IH group compared to the $\mathrm{N}$ group (Table 1) with $79.8 \pm 9.3 \mathrm{~kg}$ and $62.2 \pm 13.9 \mathrm{~kg}$ being the final absolute load achieved in their respective conditions. However, similar relative increases in this variable were found for both groups when comparing the final values (IH: $8.2 \%, P=0.007$; N: $9.8 \%, P=0.03$; Figure 2 ).

In regard to power output, higher values of both absolute and relative values were also found in the IH group compared to the $\mathrm{N}$ group (Table 1) with the $\mathrm{IH}$ group achieving $50.1 \pm$ $3.7 \mathrm{~W} \cdot \mathrm{kg}^{-1}$ in the last training session while the $\mathrm{N}$ group achieved $44.8 \pm 4.8 \mathrm{~W} \cdot \mathrm{kg}^{-1}(P=0.007)$. Furthermore, in the IH group improvements in $\mathrm{P}_{\text {rel }}$ also displayed a significant "session" main effect $\left(F=6.3, P<0.001, \eta_{p}^{2}=0.2\right)$ by increasing significantly at the end of the $\mathrm{R}_{\mathrm{T}}$ program when compared to the first session (vs. seventh and eight; $P<0.001$, Figure 3). The improvement in $\mathrm{P}_{\text {rel }}$ was also reached faster in $\mathrm{IH}$ (from session 1 vs. 4 and following; $P<0.05)$ compared to $\mathrm{N}$ [at session 1 vs. $8, P=0.19$; $95 \% \mathrm{IC}(-3.2 ;-0.4)]$. When the pre-post comparison in terms of $\mathrm{P}_{\text {rel }}$, both groups displayed improvements in this variable $(\mathrm{N}$ : $3.7 \% \mathrm{~W} \cdot \mathrm{kg}^{-1}$ and $\left.\mathrm{IH}: 7.0 \% \mathrm{~W} \cdot \mathrm{kg}^{-1}\right)$; however, the improvement was only significant in the IH group [pre: $50.7 \mathrm{~W} \cdot \mathrm{kg}^{-1}$ vs. post: $\left.54.1 \mathrm{~W} \cdot \mathrm{kg}^{-1} ; P=0.002\right)$.

For intra session VL, no differences between groups ( $F=0.9$, $\left.P=0.36, \eta_{p}^{2}=0.04 ; F=0.14\right)$ or "session" $\left(P=0.34, \eta_{p}^{2}=0.05\right)$ were detected throughout the $\mathrm{R}_{\mathrm{T}}$ period.

\section{Arterial Oxygen Saturation}

The average $\mathrm{SaO}_{2}$ values were significantly lower in $\mathrm{IH}$ compared to $\mathrm{N}$, both before ( $93.6 \pm 2.1$ vs. $97.7 \pm 0.9 \% ; F=47.8, P<$ $\left.0.001, \eta_{p}^{2}=0.7\right)$ and after the program $(93.6 \pm 1.5$ vs. $97.0 \pm$ $0.8 \% ; F=78.7, P<0.001, \eta_{p}^{2}=0.8$ ). Significant differences between pre and post session $\mathrm{SaO}_{2}$ values were found only in 


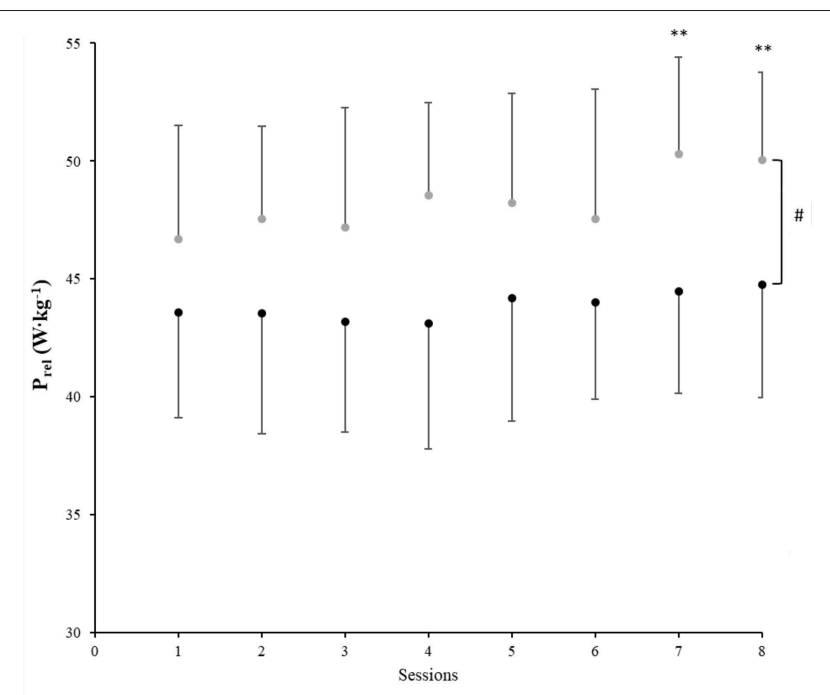

FIGURE 3 | Session averaged relative peak power $\left(P_{\text {rel }}\right) \pm$ SD during the $5 \times$ 6 repetitions-set exercises for both groups $(\mathrm{IH}: \square, \mathrm{N}: \mathbf{\square})$, across the 4-weeks $\mathrm{R}_{\mathrm{T}}$ program. Significant differences were ${ }^{* \star}$ among sessions (compared with the first session, $P<0.001)$ and $\#$ between groups $(P<0.05)$.

$\mathrm{N}\left(F=22.0, P=0.001, \eta_{p}^{2}=0.7\right)$, with lower values observed after the session.

\section{Rating of Perceived Exertion}

Table 1 shows the mean RPE per group. Greater RPE values were observed in $\mathrm{IH}$ when compared with $\mathrm{N}$ for all the unpaired sessions $(6.8 \pm 1.5$ vs. $5.6 \pm 2$ a.u, $P<0.001$, respectively; Figure 4).

\section{DISCUSSION}

The aim of this study was to examine the viability of the MPV to adjust the individual load during a power-oriented $\mathrm{R}_{\mathrm{T}}$ program at moderate altitude. The similar response observed between the groups in terms of relative load (Figure 2), combined with the lack of differences in VL between groups supports the use of MPV as a viable strategy to adjust the external training load at moderate altitude, as previously tested at sea level (Izquierdo et al., 2006; González-Badillo and Sánchez-Medina, 2010). On the other hand, the higher RPE values and the greater displaced load seen in the IH group suggest that, "velocity-based training" at moderate altitude increases both the internal and the external load. Therefore, it seems that in hypoxia the physiological stress imposed by the training session at $1 \mathrm{~m} / \mathrm{s}$ is higher than in normoxia. For this reason, it is recommended to also monitor the internal load when using the MPV; in this way, coaches are more informed as to the real physiological stress associated with the $\mathrm{R}_{\mathrm{T}}$ session. It is worth mentioning that despite the training effect, higher $\mathrm{P}_{\text {rel }}$ values and faster improvements in this parameter were reached in the IH group when compared to N. This could be interpreted as an increased effectiveness of the $\mathrm{R}_{\mathrm{T}}$ at altitude.

It is well-known that exercise in hypoxia relies on a greater contribution from the anaerobic energy systems, accelerating the production of metabolites, which in turn may have positive effects on the strength responses due to an enhanced muscle activation (Kawada, 2005; Schoenfeld, 2013). In addition, several studies suggest that low levels of $\mathrm{SaO}_{2}$ can induce the recruitment of additional type II fibers (Kon et al., 2010; Schoenfeld, 2013). Manimmanakorn et al. (2013) observed that breathing air with low $\mathrm{O}_{2}$ content is a primary trigger for muscle fiber transition (from type I to II), making the movement faster because of the larger motor neurons' capability to conduct impulses at higher velocities (Manimmanakorn et al., 2013). Thus, at altitude, the $\mathrm{P}_{\text {rel }}$ production could be also related to the recruitment of more fast-twitch fibers (type II), which are primarily glycolytic, playing an important role for the energy supply during $\mathrm{R}_{\mathrm{T}}$ (Maffiuletti et al., 2016). However, during isolated explosive movements, the hypoxic benefits on performance have been found only in hypobaric hypoxia and not in normobaric hypoxia (Feriche et al., 2014; Scott et al., 2015). Thus, despite the fact that both groups started the 4week program in their corresponding environmental condition, having similar levels of displaced load (first session, $N$ : $-3.7 \mathrm{Kg}$, $P>0.05$; IH: $+4.9 \mathrm{Kg} ; P=0.046$ with respect the pre-test in $\mathrm{N}$ conditions), it seems that the moderate altitude $(2,300 \mathrm{~m})$ characteristics (reduced resistance of the air and lower $\mathrm{PaO}_{2}$ ) combined with the muscle response to the hypoxic stimulus (an increased recruitment of high-threshold type II fibers) would have had a positive effect not only on the amount of weight displaced but also on the load-velocity relationship in IH (Feriche et al., 2014; García-Ramos et al., 2016a). This hypothesis is supported by the fact that, on average, the $\mathrm{IH}$ group showed lower values of $\mathrm{SaO}_{2}$ and higher values in all external load markers (Table 1).

Our results lend support to the findings of other studies that reported increases in both maximal peak velocities and power output at the end of a power-oriented $\mathrm{R}_{\mathrm{T}}$ period in chronic (García-Ramos et al., 2016b), or intermittent natural altitude (Morales-Artacho et al., 2018). Therefore, it seems likely that muscle function is not impaired by acute or chronic exposure to moderate altitude in comparison to normoxia (García-Ramos et al., 2016b), and it may in fact be enhanced after a training period at altitude (García-Ramos et al., 2016b; Morales-Artacho et al., 2018). Conversely, in a study in which subjects were exposed to normobaric hypoxia (breathing through a mask connected to a hypoxic generator), no differences were found regarding $\mathrm{P}_{\text {rel }}$ when executing $\mathrm{CMJ}$ in normoxia $\left(\mathrm{FiO}_{2} 21 \%\right)$, moderate hypoxia $\left(\mathrm{FiO}_{2} 16 \%\right)$ and "high altitude" $\left(\mathrm{FiO}_{2} 13 \%\right)$, probably due to all the conditions being tested under the same barometric pressure (Ramos-Campo et al., 2016).

As previously mentioned, monitoring the velocity loss can be used to determine the presence of neuromuscular fatigue with the concomitant impaired performance during $\mathrm{R}_{\mathrm{T}}$ as an increase in this parameter is related to markers of metabolic stress (Sánchez-Medina and González-Badillo, 2011). The fact that we found a similar pattern in VL between groups during the $\mathrm{R}_{\mathrm{T}}$ program (Figure 3 ) could be interpreted as evidence that muscular function did not deteriorate in the IH group. We had hypothesized that with the load properly adjusted $\left(1 \mathrm{~m} \cdot \mathrm{s}^{-1}\right.$ of MPV) for each individual session, the level of neuromuscular 


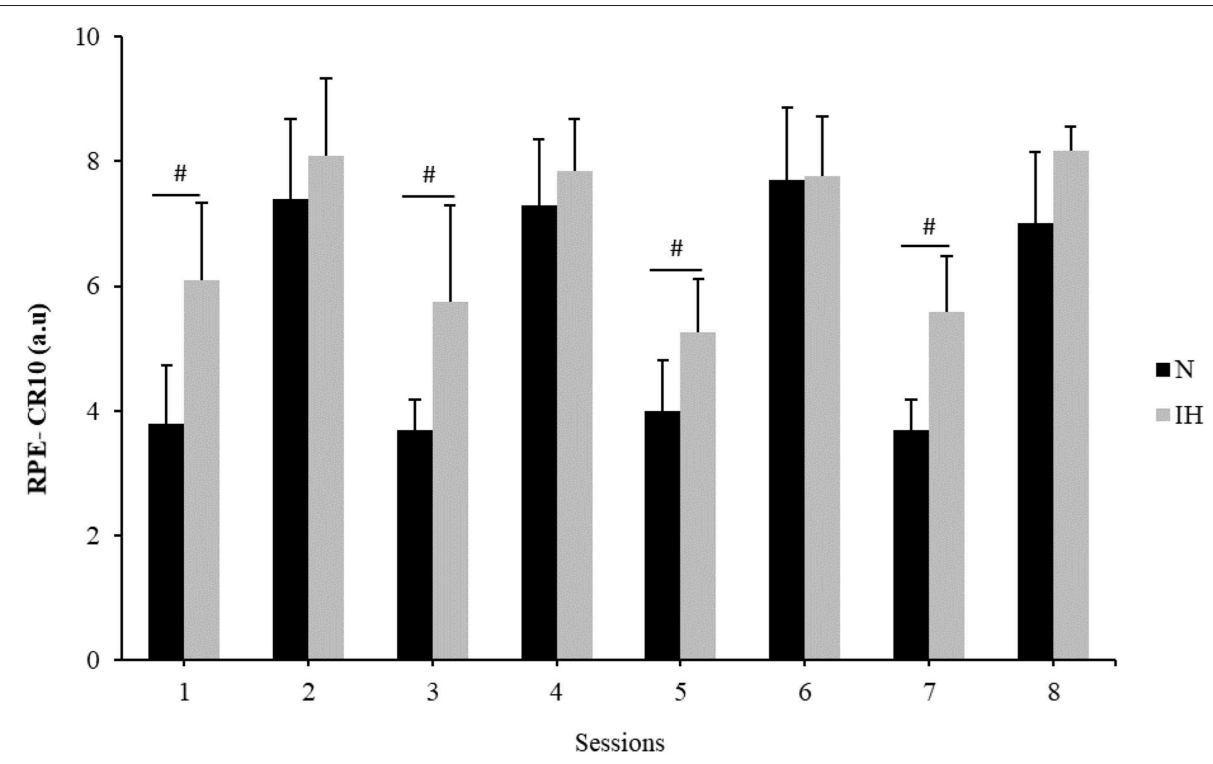

FIGURE 4 | RPE-CR10 (a.u) scores of both groups (IH: $\square, \mathrm{N}$ :

for each training session. \# Significant differences $(P<0.05)$ were between groups.

fatigue would be similar under both conditions; this hypothesis was confirmed.

On the other hand, RPE is one of the most common means of assessing internal load. It is known that athletes who exhibit a higher internal load to standardized external load may be losing fitness or suffering from fatigue (Impellizzeri et al., 2018). The combination of both internal and external load markers may indicate what kind of fatigue the athlete is suffering from Impellizzeri et al. (2018). While muscle fatigue increases the HR, RPE, and VL (Marcora et al., 2008; Sánchez-Medina and González-Badillo, 2011), mental fatigue increases only RPE (Marcora et al., 2009). Given that the IH group showed higher levels of RPE (Figure 4) with a similar VL pattern than $\mathrm{N}$ (Figure 2), it is plausible to speculate that the IH participants were more mentally fatigued. We hypothesized that hypoxia combined with exercise would have had a greater influence on RPE than those related to exercise in normoxia (Pandolf, 2001). It is well-known that RPE can be used to measure the effort during $\mathrm{R}_{\mathrm{T}}$ (Gearhart et al., 2002), with perception purportedly related to metabolic stress markers and the magnitude of muscle activation (Lagally et al., 2002). When exercise is performed in normoxia and hypobaric hypoxia at the same relative intensity $\left(1 \mathrm{~m} \cdot \mathrm{s}^{-1}\right.$ of $\mathrm{MPV}$ ), certain physiological responses are altered (e.g., reduction in $\mathrm{SaO}_{2}$ ), accounting for the increased RPE values in IH (Pandolf, 2001). The metabolic needs of the lower extremities can also increase RPE values because more muscle mass is at work (Marais et al., 2001). It therefore follows that the same muscle groups working in hypoxia would evoke higher RPE values. Our results are consistent with those of Ramos-Campo et al. (2016), who showed differences in RPE between normoxia ( $\sim$ sea level) and high altitude $(\sim 3,800 \mathrm{~m})$ after a $\mathrm{R}_{\mathrm{T}}$ circuit (Ramos-Campo et al., 2016).

Statistical analysis showed that sessions at $\mathrm{IH}$ during the unpaired days were considered harder than at sea level (Figure 4). Several studies have suggested that RPE during $\mathrm{R}_{\mathrm{T}}$ may be more dependent on the intensity than on the set volume (Gearhart et al., 2002; Day et al., 2004) due to a greater fatigability of type II fibers. Sweet et al. (2004) reported a positive relationship between intensity and $\mathrm{RPE}$ during $\mathrm{R}_{\mathrm{T}}$, whereby a high force or power output during the first part of the session conceivably fatigued the type II fibers so they were unable to perform over an extended period. Thus, high repetition protocols that engage a greater use of the type II fibers are perceived as harder than comparable intensities of steady-state aerobic exercise on a cycle ergometer (Sweet et al., 2004). Our results support this theory as the IH group who had higher RPE values also improved $\mathrm{P}_{\text {rel }}$ faster than $\mathrm{N}$ (Figure 3). Another factor that could have influenced the RPE during the unpaired sessions are the plyometric exercises (Figure 1). It is well-known that during plyometric exercises muscles are trained under tensions greater than those achieved by conventional resistance training (Holcomb et al., 1996), which in turn may increase the intensity of effort in the exercise performed. Given these results, we speculate that the combination of hypoxia and intense exercises may explain RPE during $\mathrm{R}_{\mathrm{T}}$ at moderate altitude. However, this hypothesis requires further investigation utilizing a broad range of intensities and altitudes above the sea level.

A limitation of the present study is that the composition of both groups ( $\mathrm{N}$ and $\mathrm{IH}$ ) were determined by convenience (participants' availability) and not truly randomized. We therefore cannot rule out the possibility that inherent initial differences between $\mathrm{N}$ and $\mathrm{IH}$ may have been present that compromised internal validity. However, the lack of significant between-group differences before starting the 4-week $R_{T}$ program, noted in any of the baseline parameters would seem to indicate this did not influence results. Monitoring another internal load parameter (e.g., HR, lactate, ammonia, creatinine...) together with the current RPE would have given us more information about the relationship between the internal and external load markers. This would have helped to better 
identify how the participants were coping with the external stimuli as a result of the MPV application.

In conclusion the present study demonstrated that $1 \mathrm{~m} \cdot \mathrm{s}^{-1}$ of MPV is a viable tool to adjust the individual load during power-oriented $\mathrm{R}_{\mathrm{T}}$ at moderate altitude. While the aim of the present study was not focusing on the effectiveness of a "live low, train high" strategy applied to $\mathrm{R}_{\mathrm{T}}$, the results revealed that the intermittent exposure to moderate altitude can be useful to enhance the relative peak power output more expeditiously than at sea level. However, the results indicate that power-oriented exercises at moderate altitude allow athletes to lift higher loads, evoking higher levels of RPE than at sea level. This suggests that the physiological stress imposed by a training session at 1 $\mathrm{m} / \mathrm{s}$ is higher in hypoxia compared to normoxia. Therefore, even though the application of velocity-based training at moderate altitude may be superior for improving performance compared to a traditional system of \%1RM, we recommend combing the use of the MPV with another internal marker to determine whether demands from the training session stimuli are appropriate.

\section{DATA AVAILABILITY STATEMENT}

The raw data supporting the conclusions of this manuscript will be made available by the authors, without undue reservation, to any qualified researcher.

\section{REFERENCES}

Allen, D. G., Lamb, G. D., and Westerblad, H. (2008). Skeletal muscle fatigue: cellular mechanisms. Physiol. Rev. 88, 287-332. doi: 10.1152/physrev.00015.2007

Amann, M., and Calbet, J. A. (2008). Convective oxygen transport and fatigue. J. Appl. Physiol. 104, 861-870. doi: 10.1152/japplphysiol.01008.2007

Amann, M., Romer, L. M., Pegelow, D. F., Jacques, A. J., Hess, C. J., and Dempsey, J. A. (2006). Effects of arterial oxygen content on peripheral locomotor muscle fatigue. J. Appl. Physiol. 101, 119-127. doi: 10.1152/japplphysiol.01596.2005

Bakeman, R. (2005). Recommended effect size statistics for repeated measures designs. Behav. Res. Methods 37, 379-384. doi: 10.3758/BF03192707

Bosco, G., Verratti, V., and Fanò, G. (2010). Performances in extreme environments: effects of hyper/hypobarism and hypogravity on skeletal muscle. Eur. J. Transl. Myol. 20, 83-90. doi: 10.4081/bam.2010.3.83

Day, M. L., Mcguigan, M. R., Brice, G., and Foster, C. (2004). Monitoring exercise intensity during resistance training using the session RPE scale. J. Strength Cond. Res. 18, 353-358. doi: 10.1519/00124278-20040500000027

Feriche, B., García-Ramos, A., Calderón-Soto, C., Drobnic, F., Bonitch-Góngora, J. G., Galilea, P. A., et al. (2014). Effect of acute exposure to moderate altitude on muscle power: hypobaric hypoxia vs. normobaric hypoxia. PLoS ONE 9:e114072. doi: 10.1371/journal.pone.0114072

Foster, C., Florhaug, J., Franklin, J. A., Gottschall, L., Hrovatin, L. A., Parker, S., et al. (2001). A new approach to monitoring exercise training. J. Strength Cond. Res. 15, 109-115. doi: 10.1519/00124278-200102000-00019

García-Ramos, A., Padial, P., de la Fuente, B., Argüelles-Cienfuegos, J., BonitchGóngora, J., and Feriche, B. (2016a). Relationship between vertical jump height and swimming start performance before and after an altitude training camp. J. Strength Cond. Res. 30, 1638-1645. doi: 10.1519/JSC.0000000000001242

García-Ramos, A., Padial, P., De la Fuente, B., Argüelles-Cienfuegos, J., BonitchGóngora, J., and Feriche, B. (2016b). The effect of acute and chronic exposure to hypobaric hypoxia on loaded squat jump performance J. Hum. Kinet. 56, 149-158. doi: 10.1515/hukin-2017-0032

\section{ETHICS STATEMENT}

The studies involving human participants were reviewed and approved by Ethics committee on Human Research, Granada University. The patients/participants provided their written informed consent to participate in this study.

\section{AUTHOR CONTRIBUTIONS}

LR-Z, PP, and BF: conceived and designed the experiments and performed the experiments. LR-Z: analyzed the data and wrote the paper. BS: checked English spelling and grammar. BS and BF: revised the paper. All the authors have reviewed and approved the manuscript prior submission.

\section{FUNDING}

The Ministry of Education, Culture and Sport of Spain under Grant DEP2015-64350-P, MINECO/FEDER, supported this work. The Örebro University provided the funding for publication.

\section{ACKNOWLEDGMENTS}

We thank the subjects for participating as well as the staff at the High Performance Center (C.A.R) of Sierra Nevada.

Gearhart, R. E. Jr., Goss, F. L., Lagally, K. M., Jakicic, J. M., Gallagher, J., Gallagher, K. I., et al. (2002). Ratings of perceived exertion in active muscle during highintensity and low-intensity resistance exercise. J. Strength Cond. Res. 16, 87-91. doi: 10.1519/00124278-200202000-00013

González-Badillo, J. J., Marques, M., and Sánchez-Medina, L. (2011). The importance of movement velocity as a measure to control resistance training intensity. J. Hum. Kinet. 29, 15-19. doi: 10.2478/v10078-011-0053-6

González-Badillo, J. J., Rodríguez-Rosell, D., Sánchez-Medina, L., Gorostiaga, E. M., and Pareja-Blanco, F. (2014). Maximal intended velocity training induces greater gains in bench press performance than deliberately slower half-velocity training. Eur. J. Sport Sci. 14, 772-781. doi: 10.1080/17461391.2014.905987

González-Badillo, J. J., and Sánchez-Medina, L. (2010). Movement velocity as a measure of loading intensity in resistance training. Int. J. Sports Med. 31, 347-352. doi: 10.1055/s-0030-1248333

Halson, S. L. (2014). Monitoring training load to understand fatigue in athletes. Sports Med. 44, 139-147. doi: 10.1007/s40279-014-0253-Z

Hamlin, M. J., Hopkins, W. G., and Hollings, S. C. (2015). Effects of altitude on performance of elite track-and-field athletes. Int. J. Sports Physiol. Perform. 10, 881-887. doi: 10.1123/ijspp.2014-0261

Holcomb, W. R., Lander, J. E., Rutland, R. M., and Wilson, G. D. (1996). The effectiveness of a modified plyometric program on power and the vertical jump. J. Strength Cond. Res. 10, 89-92. doi: 10.1519/00124278-199605000-00005

Impellizzeri, F. M., Marcora, S. M., and Coutts, A. J. (2018). Internal and external training load: 15 years on. Int. J. Sports Physiol. Perform. 14, 270-273. doi: 10.1123/ijspp.2018-0935

Izquierdo, M., González-Badillo, J. J., Häkkinen, K., Ibanez, J., Kraemer, W., Altadill, A., et al. (2006). Effect of loading on unintentional lifting velocity declines during single sets of repetitions to failure during upper and lower extremity muscle actions. Int. J. Sports Med. 27, 718-724. doi: 10.1055/s-2005-872825

Jiménez-Reyes, P., Samozino, P., Pareja-Blanco, F., Conceição, F., CuadradoPeñafiel, V., González-Badillo, J. J., et al. (2017). Validity of a simple method for measuring force-velocity-power profile in countermovement jump. Int. J. Sports Physiol. Perform. 12, 36-43. doi: 10.1123/IJSPP.2015-0484 
Kawada, S. (2005). What phenomena do occur in blood flow-restricted muscle? Int. J. KAATSU Train. Res. 1, 37-44. doi: 10.3806/ijktr.1.37

Kon, M., Ikeda, T., Homma, T., Akimoto, T., Suzuki, Y., and Kawahara, T. (2010). Effects of acute hypoxia on metabolic and hormonal responses to resistance exercise. Med. Sci. Sports Exerc. 42, 1279-1285. doi: 10.1249/MSS.0b013e3181ce61a5

Lagally, K. M., Robertson, R. J., Gallagher, K. I., Goss, F. L., Jakicic, J. M., Lephart, S. M., et al. (2002). Perceived exertion, electromyography, and blood lactate during acute bouts of resistance exercise. Med. Sci. Sports Exerc. 34, 552-559; discussion 560. doi: 10.1097/00005768-200203000-00025

Loturco, I., Nakamura, F. Y., Tricoli, V., Kobal, R., Cal Abad, C. C., Kitamura, K., et al. (2015). Determining the optimum power load in jump squat using the mean propulsive velocity. PLoS ONE 10:e0140102. doi: 10.1371/journal.pone.0140102

Lundby, C., Calbet, J. A., and Robach, P. (2009). The response of human skeletal muscle tissue to hypoxia. Cell. Mol. Life Sci. 66, 3615-3623. doi: 10.1007/s00018-009-0146-8

Maffiuletti, N. A., Aagaard, P., Blazevich, A. J., Folland, J., Tillin, N., and Duchateau, J. (2016). Rate of force development: physiological and methodological considerations. Eur. J. Appl. Physiol. 116, 1091-1116. doi: 10.1007/s00421-016-3346-6

Manimmanakorn, A., Manimmanakorn, N., Taylor, R., Draper, N., Billaut, F., Shearman, J. P., et al. (2013). Effects of resistance training combined with vascular occlusion or hypoxia on neuromuscular function in athletes. Eur. J. Appl. Physiol. 113, 1767-1774. doi: 10.1007/s00421-013-2605-z

Marais, G., Dupont, L., Garcin, M., Vanvelcenaher, J., and Pelayo, P. (2001). RPE responses during arm and leg exercises: effect of variations in spontaneously chosen crank rate. Percept. Mot. Skills 92, 253-262. doi: 10.2466/pms.2001.92.1.253

Marcora, S. M., Bosio, A., and de Morree, H. M. (2008). Locomotor muscle fatigue increases cardiorespiratory responses and reduces performance during intense cycling exercise independently from metabolic stress. Am. J. Physiol.-Regul. Integr. Comp. Physiol. 294, R874-R883. doi: 10.1152/ajpregu. 00678.2007

Marcora, S. M., Staiano, W., and Manning, V. (2009). Mental fatigue impairs physical performance in humans. J. Appl. Physiol. 106, 857-864. doi: 10.1152/japplphysiol.91324.2008

McLaren, S. J., Smith, A., Spears, I. R., and Weston, M. (2017). A detailed quantification of differential ratings of perceived exertion during teamsport training. J. Sci. Med. Sport 20, 290-295. doi: 10.1016/j.jsams.2016. 06.011

Morales-Artacho, A. J., Padial, P., García-Ramos, A., Pérez-Castilla, A., ArgüellesCienfuegos, J., De la Fuente, B., et al. (2018). Intermittent resistance training at moderate altitude: effects on the force-velocity relationship, isometric strength and muscle architecture. Front. Physiol. 9:594. doi: 10.3389/fphys.2018. 00594

Morree, H. M., Klein, C., and Marcora, S. M. (2012). Perception of effort reflects central motor command during movement execution. Psychophysiology 49, 1242-1253. doi: 10.1111/j.1469-8986.2012.01399.x

Pandolf, K. B. (2001). Rated perceived exertion during exercise in the heat, cold or at high altitude. Int. J. Sport Psychol. 32, 162-176.
Pérez-Castilla, A., García-Ramos, A., Padial, P., Morales-Artacho, A. J., and Feriche, B. (2018). Load-velocity relationship in variations of the halfsquat exercise: Influence of execution technique. J. Strength Cond. Res. doi: 10.1519/JSC.0000000000002072. [Epub ahead of print].

Psycharakis, S. G. (2011). A longitudinal analysis on the validity and reliability of ratings of perceived exertion for elite swimmers. J. Strength Cond. Res. 25, 420-426. doi: 10.1519/JSC.0b013e3181bff58c

Ramos-Campo, D. J., Rubio-Arias, J. A., Dufour, S., Chung, L., Ávila-Gandía, V., and Alcaraz, P. E. (2017). Biochemical responses and physical performance during high-intensity resistance circuit training in hypoxia and normoxia. Eur. J. Appl. Physiol. 117, 809-818. doi: 10.1007/s00421-017-3571-7

Ramos-Campo, D. J., Rubio-Arias, J. Á., Freitas, T. T., Camacho, A., Jiménez-Diaz, J. F., and Alcaraz, P. E. (2016). Acute physiological and performance responses to high-intensity resistance circuit training in hypoxic and normoxic conditions. J. Strength Cond. Res. 31, 1040-1047. doi: 10.1519/JSC.0000000000001572

Sánchez-Medina, L., and González-Badillo, J. J. (2011). Velocity loss as an indicator of neuromuscular fatigue during resistance training. Med. Sci. Sports Exerc. 43, 1725-1734. doi: 10.1249/MSS.0b013e318213f880

Schoenfeld, B. J. (2013). Potential mechanisms for a role of metabolic stress in hypertrophic adaptations to resistance training. Sports Med. 43, 179-194. doi: 10.1007/s40279-013-0017-1

Scott, B. R., Duthie, G. M., Thornton, H. R., and Dascombe, B. J. (2016a). Training monitoring for resistance exercise: theory and applications. Sports Med. 46, 687-698. doi: 10.1007/s40279-015-0454-0

Scott, B. R., Goods, P. R., and Slattery, K. M. (2016b). High-intensity exercise in hypoxia: is increased reliance on anaerobic metabolism important? Front. Physiol. 7:637. doi: 10.3389/fphys.2016.00637

Scott, B. R., Slattery, K. M., Sculley, D. V., Hodson, J. A., and Dascombe, B. J. (2015). Physical performance during high-intensity resistance exercise in normoxic and hypoxic conditions. J. Strength Cond. Res. 29, 807-815. doi: 10.1519/JSC.0000000000000680

Scott, B. R., Slattery, K. M., Sculley, D. V., Lockhart, C., and Dascombe, B. J. (2016c). Acute physiological responses to moderate-load resistance exercise in hypoxia. J. Strength Cond. Res. 26, 611-617. doi: 10.1519/JSC.0000000000001649

Sweet, T. W., Foster, C., Mcguigan, M. R., and Brice, G. (2004). Quantitation of resistance training using the session rating of perceived exertion method. $J$. Strength Cond. Res. 18, 796-802. doi: 10.1519/00124278-200411000-00020

Conflict of Interest: The authors declare that the research was conducted in the absence of any commercial or financial relationships that could be construed as a potential conflict of interest.

Copyright (๑ 2019 Rodríguez-Zamora, Padial, Schoenfeld and Feriche. This is an open-access article distributed under the terms of the Creative Commons Attribution License (CC BY). The use, distribution or reproduction in other forums is permitted, provided the original author(s) and the copyright owner(s) are credited and that the original publication in this journal is cited, in accordance with accepted academic practice. No use, distribution or reproduction is permitted which does not comply with these terms. 